\section{Towards a pollution policy}

\author{
Richard Sandbrook outlines how a UNEP plan \\ could help to save the Mediterranean from pollution
}

\begin{abstract}
$\mathrm{T}$ HERE are many indicators that the so-called environmental debate has moved on from its more sensational phase into a new and more difficult stage of human endeavour, at least as far as pollution questions are concerned. The catch phrases - 'limits to growth', 'spaceship Earth', 'the environment revolution'-do not excite the media or its readers any more, much less governments. Anti-pollution legislation is no longer pushed through the world's parliaments, the UN or the EEC on a wave of public alarm and high idealism. It is becoming increasingly necessary to present solid scientific evidence of harm and an economic evaluation of benefits and costs before controls gain political support.
\end{abstract}

This trend is becoming evident in certain sections of the United Nations Environment Programme (UNEP) too. Born in Stockholm in 1972 on a crescendo of 'environmental' enthusiasm, it is now struggling to survive in the harsh world of international law, inflation-prone economies and hard scientific evaluation. But in one area at least UNEP has made this shift successfully. Its Mediterranean Programme is one of the most complex international pollution control and environmental protection exercises ever undertaken. It reinforces the trend toward regional rather than global approaches to environmental protection -at least for the marine environment; and it helps to marshal together many of the previously competing UN agencies, governmental institutions and independent research units that can play a role.

Intergovernmental consultations on the programme started in February 1974, with the Food and Agricultural Organisation (FAO) meeting on the protection of living resources from pollution. UNEP became involved that year and in February 1975 convened an intergovernmental meeting in Barcelona on the general protection of the Mediterranean. The gathering discussed the first draft of a framework or 'umbrella' convention for the protection of the Mediterranean, and approved a three-part programme encompassing legal arrangements, scientific research and monitoring and integrated planning for the region.

A year later, in February 1976, the umbrella convention was finally approved by 16 of the 18 Mediterranean

Richard Sandbrook is at the International Institute for Environment and Development, London. states (the exceptions being Algeria and Albania), together with two specific protocols attached to it on the prevention of pollution by dumping (ships and aircraft) and on intergovernmental cooperation in the event of a pollution emergency. The convention was very broad, committing states to "take all appropriate measures . . . to prevent, abate and combat pollution of the Mediterranean Sea area and to protect and enhance the marine environment". A signed convention is far from a ratified convention, however, and a ratified convention is in turn far from a working one. The 1969 amendments to the IMCO 1954 oil pollution convention, for example, only came into force after the required number of ratifications in Janaury of this year; it will be a further year at least before it is working.

Will the Mediterranean agreements suffer the same fate? One suspects not, for the convention and the two protocols to date are but a part of the much wider environmental programme -driven on, in the northern Mediterranean at least, by the threat of reduced tourism, waterborne health risks and highly contaminated marine life locally. In March 1975, for example, the French Institute of Medical Oceanography issued a wanning that if mercury pollution continued at its current rate then fishermen and others who consumed on average two kilos of certain local fish a week would be chronically ill within 7 years and dead in 20 from mercury poisoning.

The legal arrangements, for example, are not going to end with ratification of the three existing instruments. A further protocol on land source pollution could be ready by the end of 1977 to be added to the framework convention, and a further protocol on exploration and exploitation of the seabed and the continental shelf is planned.

\section{Questioning the rationale}

The rationale for this grand plan, at least on an international level, is often questioned. Why not leave pollution control up to individual states or at most neighbouring states? Is it simply following a fashion set by the Oslo and London dumping conventions and the Paris convention on land source pollution?* Or do the coastal states really believe that an integrated and regional approach is necessary?

The geography of the region provides some explanation. The Mediter- ranean Sea is a semi-enclosed sea and its water is effectively divided into two basins (north and south) which rotate cyclonically. In this way pollutants cross national frontiers; those from Italy potentially affect France, and those from the Nile Israel. The currents hug the coasts and such ship-source pollutants as floating litter and tar tend to be spun centrifugally toward them. Saline water enters the sea in the surface waters of the Straits of Gibraltar and leaves by the same route at greater depth. The average estimated residence time of the water is of the order of 80 years, although the range is probably from a few to several hundred years. This in effect means that for those long-lived and stable pollutants accumulation over time is bound to occur.

Secondary to the transfrontier rationale is the monitoring and research needed to underpin environmental controls. Given that the first step in controlling any pollutant is to know its source, its concentration and then its effect, the idea of monitoring the sea as a whole for the three sets of variables makes eminent good sense politically and for the more mobile and persistent pollutants good sense scientifically. This monitoring work is now progressing on seven fronts throughout the Mediterranean basin:

-Baseline studies and monitoring of oil and petroleum hydrocarbons, in conjunction with the Intergovernmental Oceanographic Commission of UNESCO and the World Meteorological Organisation. This programme, which now involves 11 of the 16 coastal states and 26 national laboratories, is focused on the new regional oil combating centre in Malta, which is run by IMCO.

- Baseline studies and monitoring of the heavy metals, particularly mercury and cadmium in marine organisms - a project sponsored by FAO and UNEP in 14 countries and 38 laboratories.

-Baseline studies and monitoring of DDT, PCBs and other chlorinated hydrocarbons-an FAO/UNEP project in 13 countries.

- Research on the effects of pollutants on marine organisms and their populations (FAO/UNEP in 11 countries). The aim is to study the effect of various pollutants on the population dynamics of certain test organisms; it is hoped the study will lead to the identification of particularly vulnerable species

*The 1972 Oslo Convention for the Prevention of The 1972 Oslo Convention for the Prevention of Marine Pollution by Dumping from Ships and Aircraft entered into force in 1974 and covers the North Sea and the northwest Atlantic. The London Convention is a plohal convention to control the dumping of wastes at sea, and entered into force in 1975: it is now ildministered by IMCO. The Paris Convention for the Prevention of Marine Pollution from Land-based Sontec covers the same are 


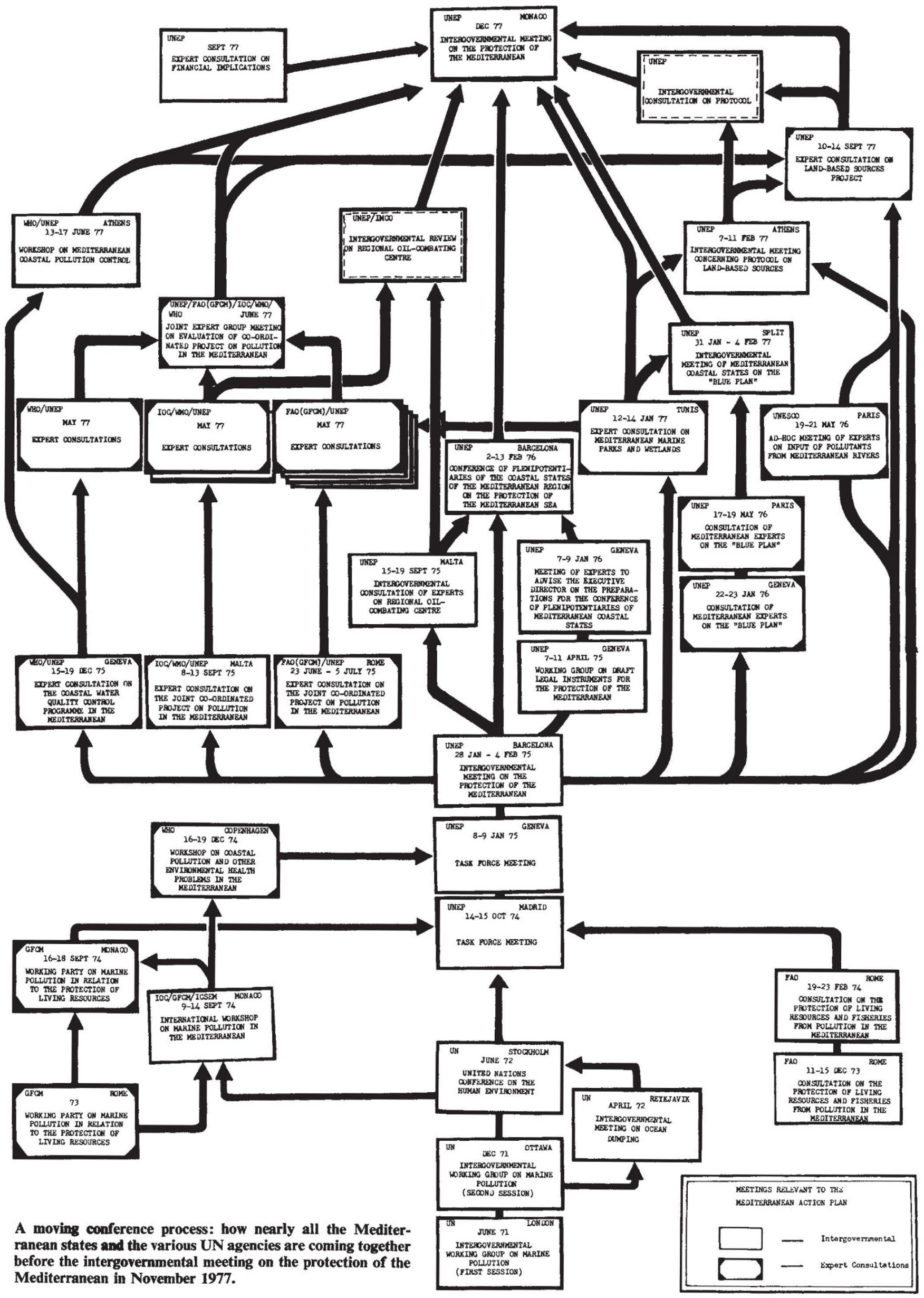


within the different tropic levels at various stages of their life cycles and in time lead to the identification of indicator species for water quality criteria.

- Research on the effects of pollutants on marine communities and ecosystems (FAO/UNEP in 12 countries). The project will amount to the intensive field study of various coastal ecosystems under stress, or of areas where ecosystem changes may be anticipated as a consequence of development and areas that are unpolluted and designated as marine parks for control purposes.

- Problems of coastal transport of pollutants (IOC/UNEP in 12 countries). The aim is to study the water circulation in coastal areas to understand better the physical transport of pollutants.

- Coastal water quality control (WHO/ UNEP in 8 countries). The overall objective of this pilot project is to produce statistically significant data on pollution levels that may affect human health.

Each of these seven projects involves a nominated 'activity centre'; also needed is the back-up support of the IAEA and UNEP on intercalibration of equipment and analytical techniques and the provision of common maintenance services for the more sophisticated laboratory instruments. A technical training programme is under way; grants for instruments and a growing number of manuals and guidelines for the participating laboratories are available.

All of this will be the backdrop against which the next protocol will emerge. It will take a form broadly similar to that adopted in Paris in 1974 for the North East Atlantic, in Helsinki in 1974 for the Baltic Sea Area and in Brussels in 1976 for European Economic Community waters. As it is being drafted midway in the seven point scientific programme, however, the hope is that after a series of evaluation meetings of the projects involved, it will avoid some of the pitfalls that the precedents have fallen into. For example, the interim body set up to help the process of ratification of the Paris convention (IPARCOM) is the arena for much disagreement. Typical questions to be answered are: What constitutes pollution? What should be monitored? And by whom and where? For the convention simply states that by pollution is meant substances ur energy introduced directly or indirectly by man that results in such deleterious effects as hazards to human health, harm to living resources and marine ecosystems, damage to amenities or interference with other legitimate uses of the sea. What is meant by 'hazards', 'harm' and 'interference' is unclear.
And on top of the work of IPARCOM (and any Mediterranean protocol developed) are the problems imposed by the European Commission directive on land source pollution (1976).

\section{Black and grey lists}

Both the Paris convention, and its later brother, the Brussels directive, include two lists (as annexes) of substances to be considered. The so-called black lists in the Paris convention relate to substances to be eliminated from the environment-for example, mercury and its compounds, persistent oils and hydrocarbons of petroleum origin, cadmium and cadmium compounds-and in the Brussels directive a similar list which is to be subject to uniform emission standards with an option for states to operate as-yet-undefined "environmental quality objectives". In both there are grey lists of substances that will be subject to less strict controls.

The treaty language is always, cf course, strong enough to sound impressive environmentally-even, as some would allege, economically. One admitted purpose behind the Brussels approach is that all states should suffer the same environmental constraints no matter where the pollution occurs-an 'equalising' of competition. But in practice things are far from simple. There is little or no quantitative evaluation of acute or chronic harm to back any standards that may be set, and no recognition of the fact that receiving environments differ. For those who want to delay ratification this provides excuse enough. But a less cynical view is that unnecessary controls are not in anyone's interests other than the pollution control equipment manufacturer -and so why have them? The British have become so upset by the arguments over Paris and the Brussels directives that they have now resorted to publishing a detailed explanation of their case (DoE Pollution Paper No 11).

This time round, Mediterranean governments who have been involved in the EEC and IPARCOM process should have an idea of the likely costs involved, the necessary levels of control that should be applied and most particularly be able to avoid the problems of definition that bedevil the precedents in the field. Not least, by having some research first, many more governments will be aware of just what is under consideration.

The final concern of the programme is that of integrated planning; here the so-called Blue Plan and the Priority Action Programme are the two components. Throughout, UNEP has been at pains to stress that it is not posturing as an executive agency for the area-a sort of unofficial Brussels for the Mediterranean basin--and the Blue
Plan reflects this. There are no 'line' responsibilities envisaged but a set of 'processes' to be developed to enable governments to take the environment into account when making their own decisions. Thus systematic surveys of all major economic growth areas are called for, and so are studies of such varied topics as soil protection, water resources and urbanisation trends. The Priority Action Programme is in essence a part of the same plan but it includes areas ready for immediate action before the overall process gets underway. Again a series of cooperating national and international agencies are included.

The catch, of course, is how much notice governments will take of the environmental advice that they receive, and to what extent the whole effort will become bogged down in regional economic disparities. It all looks dangerously like the European Commission but without the teeth of its Council. To a certain extent, governments will become locked into a process that will ensure compliance-the major aid agencies (UNDP and the World Bank) that are helping some of the southern coastal states are going to be influenced by the development criteria agreed under the plan's auspices. Similarly, FAO who are developing the fisheries and WHO who are helping to build up sanitation infrastructures in the southern states are going to be closely involved. However, both components are small in resources. The first phase, costing an estimated $\$ 1.5$ million in total will, one suspects, be little more than an exchange between planners and development strategists.

This is not to knock too much. It is after all remarkable that Greece should sit with Turkey--Israel with Egyptand talk over such important domestic strategies at all, and if the approach of the Mediterranean programme goes well it is likely to spread to other regional waters-the Persian/Arabian Gulf, the Caribbean Sea and the West African coastline for example.

There is no doubt that the unified scientific monitoring will lead to progress first in our understanding of the marine ecosystem and maybe then in controlling the obvious pollution that is going on. Governments are discovering disturbing levels of heavy metal contamination and waterborne disease in their waters. These facts are going to be made public one day and that is going to ensure a change in the level of investment and control exercised. Cousteau, who in 1972 said that the Mediterranean would surely die, admits that much progress. In 1976 , he sent a telegram to UNEP saying that it might live after all. 